\title{
Influence of Temperature, Relative Humidity, Ascospore Concentration, and Length of Drying of Colonized Dry Bean Flowers on White Mold Development
}

\author{
R. Harikrishnan and L. E. del Río, Department of Plant Pathology, North Dakota State University, Fargo 58105
}

\begin{abstract}
Harikrishnan, R., and del Río, L. E. 2006. Influence of temperature, relative humidity, ascospore concentration, and length of drying of colonized dry bean flowers on white mold development. Plant Dis. 90:946-950.

Growth chamber studies were conducted using rehydrated dry bean (Phaseolus vulgaris) flowers $(\mathrm{RDBF})$ to assess the influence of temperature $\left(18\right.$ and $\left.22^{\circ} \mathrm{C}\right)$, relative humidity (RH; 25 and $90 \%$ ), and ascospore concentrations $\left(10^{2}, 10^{3}\right.$, and $10^{4}$ ascospores $\left./ \mathrm{ml}\right)$ on white mold incidence in dry bean. Additional studies were carried out to determine the influence of inoculum type (ascospore and mycelium) and to estimate the effect of duration of drying of colonized RDBF on viability of Sclerotinia sclerotiorum and white mold incidence. There was a linear increase in white mold incidence with increase in ascospore concentration but neither temperature nor RH levels significantly affected disease development. In the inoculum type study, both temperature and RH levels significantly affected white mold incidence; however, neither ascospore nor mycelial inocula had a significant effect on white mold incidence. Drying colonized RDBF for up to $96 \mathrm{~h}$ did not affect $S$. sclerotiorum viability; but the amount of white mold incidence depended more on post-inoculation RH and drying duration than on the temperatures tested. Colonized RDBF dried for $96 \mathrm{~h}$ took approximately three times longer to achieve $100 \%$ white mold incidence compared with colonized RDBF dried for $24 \mathrm{~h}$. These results suggest the potential for greater white mold development with higher ascospore availability and the potential of dry $S$. sclerotiorum-colonized dry bean flowers as a viable inoculum source.
\end{abstract}

Additional keyword: epidemiology

Sclerotinia sclerotiorum (L.) de Bary is a necrotrophic fungal pathogen with worldwide distribution and with the capability of infecting several economically important crops, including dry bean (Phaseolus vulgaris L.; 6). North Dakota leads the nation both in terms of area and production of dry bean (11). White mold caused by $S$. sclerotiorum is endemic in the state and is considered by growers to be one of the leading production constraints (7). Several aspects of the epidemiology of diseases caused by $S$. sclerotiorum have been well documented (25,8). Among the various abiotic factors that influence diseases caused by $S$. sclerotiorum, temperature and moisture are considered the most influential (2). In general, cooler and wetter conditions favor diseases caused by S. sclerotiorum (2).

Ascospores produced by mature apothecia are the primary infective propagules of S. sclerotiorum (15). Apothecia are produced from sclerotia, which are the survival structure of $S$. sclerotiorum following conditioning under long periods of cool

Corresponding author: L. E. del Río

E-mail: luis.delrio-mendoza@ndsu.edu

Accepted for publication 10 March 2006.

DOI: 10.1094/PD-90-0946

(C) 2006 The American Phytopathological Society and moist conditions (14). It has been postulated that ascospores require free water for germination and infection, with senescent plant tissue or bean blossoms serving as an exogenous nutritional source for the germinating ascospores $(1,5)$. After colonization of senescent tissue, the fungus invades green living tissue in contact with the blossoms and spreads to other parts of the plant.

There is no complete physiological resistance available for white mold in dry bean; however, several host characteristics, such as canopy density, blossoming traits, and growth habit, all have been shown to influence the microclimate and, thus, white mold development (13). Cultivars with open canopy and determinate growth habit provide for better air circulation both within rows and between plants and, thus, have drier microclimates compared with cultivars with closed canopy and indeterminate growth habit, which allow lesser air circulation and more dew accumulation on the plant surface, conditions that are favorable for diseases caused by $S$. sclerotiorum (3).

Field observations over the past several growing seasons in North Dakota reveal an average 10 to $15 \%$ incidence (affected plants/field) every year (10). However, in years of cooler weather, such as 2004, average white mold incidence almost doubled (personal observation). In North Dakota growing conditions, temperature normally is not a limiting factor. Maximum temperature during the growing season (May through August) ranges from 18 to $27^{\circ} \mathrm{C}$ (30-year average), which is well within the optimum limits for diseases caused by $S$. sclerotiorum. However, the more limiting weather variable in our growing conditions for white mold development is moisture. Based on these observations, we wanted to evaluate the influence of moisture within the optimum temperature range to further elucidate white mold development. Additionally, the impact of microclimatic conditions during and following deposition of ascospores on the blossoms and their subsequent effect on infection and colonization are not well understood. With this in mind, the following objectives were evaluated using rehydrated dry bean flowers (RDBF) as a nutrient source: (i) the influence of temperature, relative humidity $(\mathrm{RH})$, and ascospore concentration on white mold development; (ii) the influence of temperature and $\mathrm{RH}$ on colonization of bean flowers by two types of inocula (ascospores and mycelia); and (iii) the effects of drying colonized bean flowers on viability of $S$. sclerotiorum and subsequent white mold development. Partial results of this study have been reported previously (9).

\section{MATERIALS AND METHODS}

Sclerotia production and conditioning. An isolate of $S$. sclerotiorum recovered from a field-infected dry bean plant in the 2004 growing season was used throughout the study. Sclerotia were produced in 250-ml conical flasks containing a mixture of sand:corn meal medium $(60 \mathrm{~g}$ of white sand and $3 \mathrm{~g}$ of yellow corn meal [Quaker, Chicago]; and $16 \mathrm{ml}$ of $0.1 \mathrm{M}$ phosphate buffer, $\mathrm{pH}$ 5.8). The medium was autoclaved at $121^{\circ} \mathrm{C}$ and $103 \mathrm{kPa}$ for $40 \mathrm{~min}$. Following cooling, the medium was seeded with two 5-mm agar disks from an $S$. sclerotiorum culture (2 to 3 days old) grown on potato dextrose agar (PDA; Difco; Becton, Dickinson and Company, Sparks, MD) and incubated at $20 \pm 1^{\circ} \mathrm{C}$ for 3 weeks. The flasks were shaken periodically to facilitate uniform colonization and to maximize sclerotia yield. At the end of the incubation period, the sclerotia were harvested by wet sieving under running tap water. Sclerotia were air dried overnight and stored at $-5^{\circ} \mathrm{C}$.

Sclerotia were conditioned by exposing them to four alternate freezing and thawing cycles of $24 \mathrm{~h}$ each at -20 and $20^{\circ} \mathrm{C}$, respectively. After the final freeze/thaw cy- 
cle, the sclerotia were stored at $-5^{\circ} \mathrm{C}$ until use.

Ascospore and mycelial inoculum production. Conditioned sclerotia were placed in petri dishes ( 90 by $15 \mathrm{~mm}$ ) containing white silica sand saturated with water, and incubated at $18 \mathrm{C} \pm 1{ }^{\circ} \mathrm{C}$ with a 12-h light (fluorescent bulbs) and dark cycle. Stipe initiation and apothecia formation took approximately 4 to 6 weeks, and another 7 to 10 days were required for maturation of apothecia. Ascospores were released continually onto the underside of the petri dish lids for a period of 10 to 14 days. Ascospores were washed off the lids with an aqueous $30 \%$ glycerol solution and stored at $-5^{\circ} \mathrm{C}$.

Mycelial inoculum was prepared by seeding potato dextrose broth (Difco; Becton, Dickinson and Company) with 2- to 3 5-mm agar plugs from a 2- to 3-day old culture in PDA of the $S$. sclerotiorum isolate and incubating for 7 to 10 days in a rotary shaker at $100 \mathrm{rpm}$ at $18 \mathrm{C} \pm 1^{\circ} \mathrm{C}$. At the end of the incubation period, mycelia were harvested using double-layered cheesecloth and macerated in a commercial blender for $1 \mathrm{~min}$. Inoculum density was estimated using serial dilution plating on PDA and was adjusted to $10^{3} \mathrm{CFU} / \mathrm{ml}$ with sterilized distilled water.

Flower conditioning and seedling production. Fully opened dry bean flowers were collected from greenhouse-grown plants of cv. Maverick, a pinto bean. Flowers were air dried overnight at $20 \pm 1^{\circ} \mathrm{C}$ and stored in parafilm-sealed petri dishes at $5 \pm 1^{\circ} \mathrm{C}$ in the refrigerator until used. Dried flowers were spread on moist tissue paper overnight at $4^{\circ} \mathrm{C}$ for rehydration prior to use. These RDBF were used as the source of initial nutrient in all the studies described below.

Seedlings of pinto bean cv. Maverick were used in all the studies. Seedlings were grown in Conetainers (13 by $8 \mathrm{~cm}$; Hummerts, St. Louis) filled with potting soil mix (Sunshine Mix 1; Sun Gro Horticulture, Vancouver, British Columbia, Canada) and were inoculated at the V1 to V2 growth stage (first to second fully opened trifoliate) in all the studies described below.

Ascospore concentration study. The study was conducted as a split-split plot experiment with two temperatures (18 and $22 \pm 2^{\circ} \mathrm{C}$; whole plot), two RH levels (25 and $90 \pm 5 \%$; split plot), and three ascospore concentrations $\left(10^{2}, 10^{3}\right.$, and $10^{4}$ ascospores $/ \mathrm{ml}$ of sterilized distilled water; split-split plot). RDBF were spotinoculated with $20 \mu \mathrm{l}$ of the respective ascospore suspensions to give a final ascospore concentration of 2, 20, and 200 ascospores/flower and were placed individually on the axis of the first node of the seedlings. The inoculated seedlings were incubated in moist chambers at all combinations of temperatures and RH levels. These chambers, locally fabricated with Plexi- glas, were monitored with different settings of cool mist humidifiers (Model 461; The Holmes Company, Inc., Milford, MA) to achieve the two different RH levels (25 and $90 \pm 5 \%$ ). For the $25 \%$ RH level, the doors were left open to provide air circulation to create a drier environment. Seedlings were maintained at a 12-h light and dark cycle with watering as needed for the duration of the experiment. During the entire course of the experiment, temperature and RH were monitored (Hobo sensors; Onset Computer Corporation, Bourne, MA), regulated, and maintained at the desired levels using air conditioners and cool mist humidifiers. The experiment was conducted twice with three replications of five plants each for every ascospore concentration-temperature-RH combination.

Inoculum type study. A factorial treatment design with two temperatures (18 and $22 \pm 2^{\circ} \mathrm{C}$ ), two RH levels ( 25 and $90 \pm$ $5 \%$ ), and two inoculum types (ascospore and mycelium) were used. RDBF were dip inoculated for 30 to $40 \mathrm{~s}$ in either a $10^{3}$ ascospores $/ \mathrm{ml}$ suspension or into a $10^{3}$ $\mathrm{CFU} / \mathrm{ml}$ of mycelial suspension. Inoculation of seedlings (same cultivar and plant age), incubation, and maintenance were carried out as described for the ascospore concentration study at all combinations of temperatures and RH levels. There were three replications of five plants each for every treatment combination and the experiment was conducted twice.

Duration of drying study. RDBF were placed onto 2- to 3-day-old S. sclerotiorum colonies growing on PDA and left overnight at $20 \pm 1^{\circ} \mathrm{C}$. The following day, the visibly colonized RDBF were left for drying at $25 \pm 5 \% \mathrm{RH}$ under either 18 or $22 \pm$ intervals over the next $96 \mathrm{~h}$, colonized $2^{\circ} \mathrm{C}$ (pre-inoculation temperature). At 24-h

RDBF from both pre-inoculation temperatures were placed singly onto the seedlings. Following inoculation, seedlings were incubated at all combinations of either 18 or $22^{\circ} \mathrm{C}$ and 25 or $90 \%$ RH (postinoculation conditions). Concurrently, viability of colonized RDBF was assessed in vitro at 24-h intervals for $144 \mathrm{~h}$ by incubating 10 colonized RDBF on PDA in the dark at $20 \pm 1{ }^{\circ} \mathrm{C}$. The study was done twice with three replications of five plants for every treatment combination per study.

Disease measurements and data analyses. For the ascospore concentration and inoculum type studies, white mold incidence, expressed as percentage of dead seedlings, was assessed daily over a period of 8 days following inoculation. For the duration of drying study, measurements were made of the days required to achieve $100 \%$ white mold following seedling inoculation with colonized RDBF.

Data from all the studies were analyzed as split-split plot using PROC GLM in SAS (version 8; SAS Institute, Cary, NC). Main factors in all studies were considered as fixed effects. Mean separation of main factors was done using Fisher's least significant difference test $(P=0.05)$.

\section{RESULTS}

Ascospore concentration study. Ascospore concentrations had a significant effect on white mold incidence $(P=$ 0.006 ). Mean white mold incidence at 2 , 20 , and 200 ascospores/flower was 28,47 , and $79 \%$, respectively. The mean white mold incidence at 25 and $90 \%$ RH levels was 54 and $49 \%$, respectively, but these values were not significantly different from each other (Fig. 1).

Inoculum type study. Temperature $(\mathrm{T})$, RH, inoculum type (IT), T-RH, T-IT, RH-

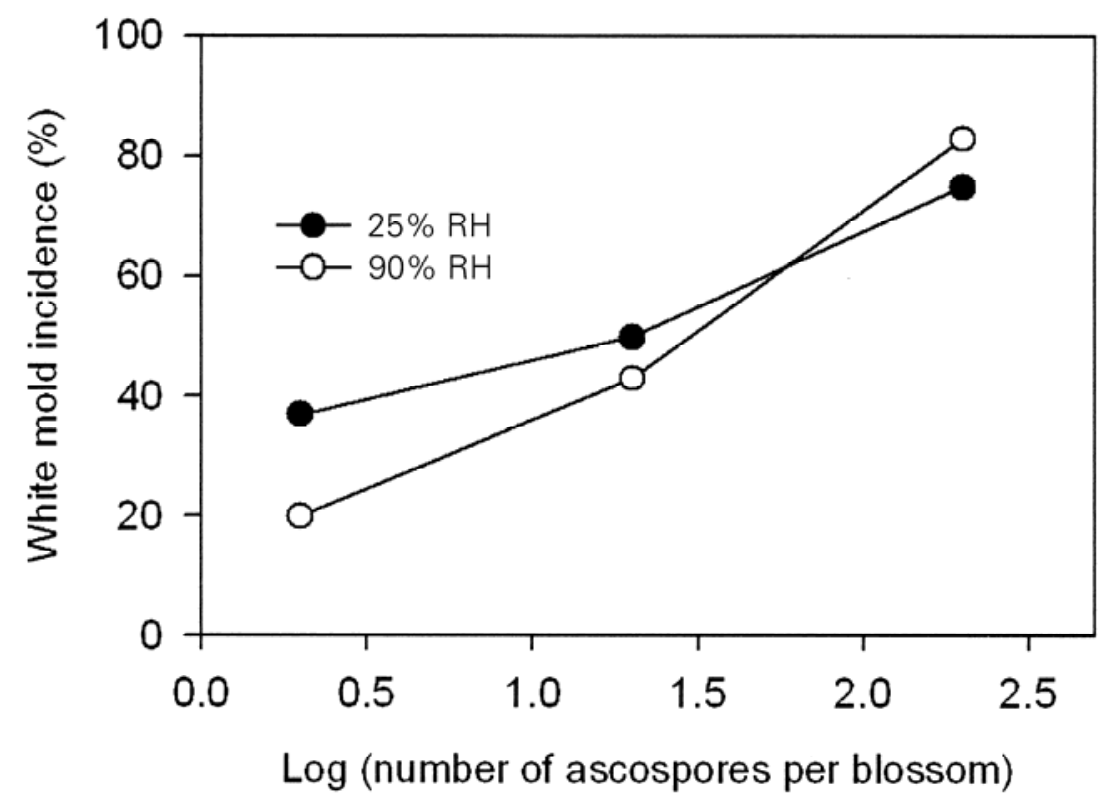

Fig. 1. Influence of two relative humidity (RH) levels and three Sclerotinia sclerotiorum ascospore concentrations on white mold incidence on dry bean in growth-chamber studies. Each data point is the mean of two temperatures $\left(18\right.$ and $\left.22^{\circ} \mathrm{C}\right)$, two experiments, and three replications of five plants each. 
IT, and three-way interactions significantly affected white mold incidence $(P \leq$ 0.06; Table 1). Within both inocula, $\mathrm{RH}$ levels differently influenced white mold incidence. Generally, white mold incidence developed faster at 18 compared with $22^{\circ} \mathrm{C}$ within each $\mathrm{RH}$ level. When seedlings inoculated with ascospores were incubated at $90 \% \mathrm{RH}$, irrespective of the temperature, white mold incidence reached $100 \%$ within 4 to 5 days. However, when incubated at $25 \% \mathrm{RH}$, white mold incidence developed almost twice as fast in seedlings at 18 compared with $22^{\circ} \mathrm{C}$ (Fig. 2A). Similar results were obtained when seedlings were inoculated with RBDF dipped in mycelial inoculum (Fig. 2B).

Table 1. Analysis of variance of the effects of temperature, relative humidity, and type of inoculum of Sclerotinia sclerotiorum on white mold incidence (\%)

\begin{tabular}{lcrrc}
\hline Source $^{\mathbf{a}}$ & df & MSE $^{\mathbf{b}}$ & $\boldsymbol{F}$ & $\boldsymbol{P}>\boldsymbol{F}$ \\
\hline $\mathrm{T}$ & 1 & $2,812.5$ & 225.0 & 0.04 \\
$\mathrm{RH}$ & 1 & $63,279.0$ & $2,407.1$ & 0.01 \\
$\mathrm{IT}$ & 1 & 294.0 & 588.3 & 0.03 \\
$\mathrm{~T} \times \mathrm{RH}$ & 1 & 66.1 & 132.3 & 0.06 \\
$\mathrm{~T} \times \mathrm{IT}$ & 1 & 406.1 & 812.2 & 0.02 \\
$\mathrm{RH} \times \mathrm{IT}$ & 1 & $2,261.3$ & $4,552.6$ & 0.01 \\
$\mathrm{~T} \times \mathrm{RH} \times \mathrm{IT}$ & 1 & 112.5 & 225.0 & 0.04 \\
\hline
\end{tabular}

${ }^{\mathrm{a}} \mathrm{T}=$ denotes incubation temperatures $\left(18\right.$ or $\left.22^{\circ} \mathrm{C}\right), \mathrm{RH}=$ relative humidity at either 25 or $90 \pm 5 \%$; and IT $=$ inoculum type (ascospores or mycelia).

${ }^{\mathrm{b}} \mathrm{MSE}=$ mean square error.

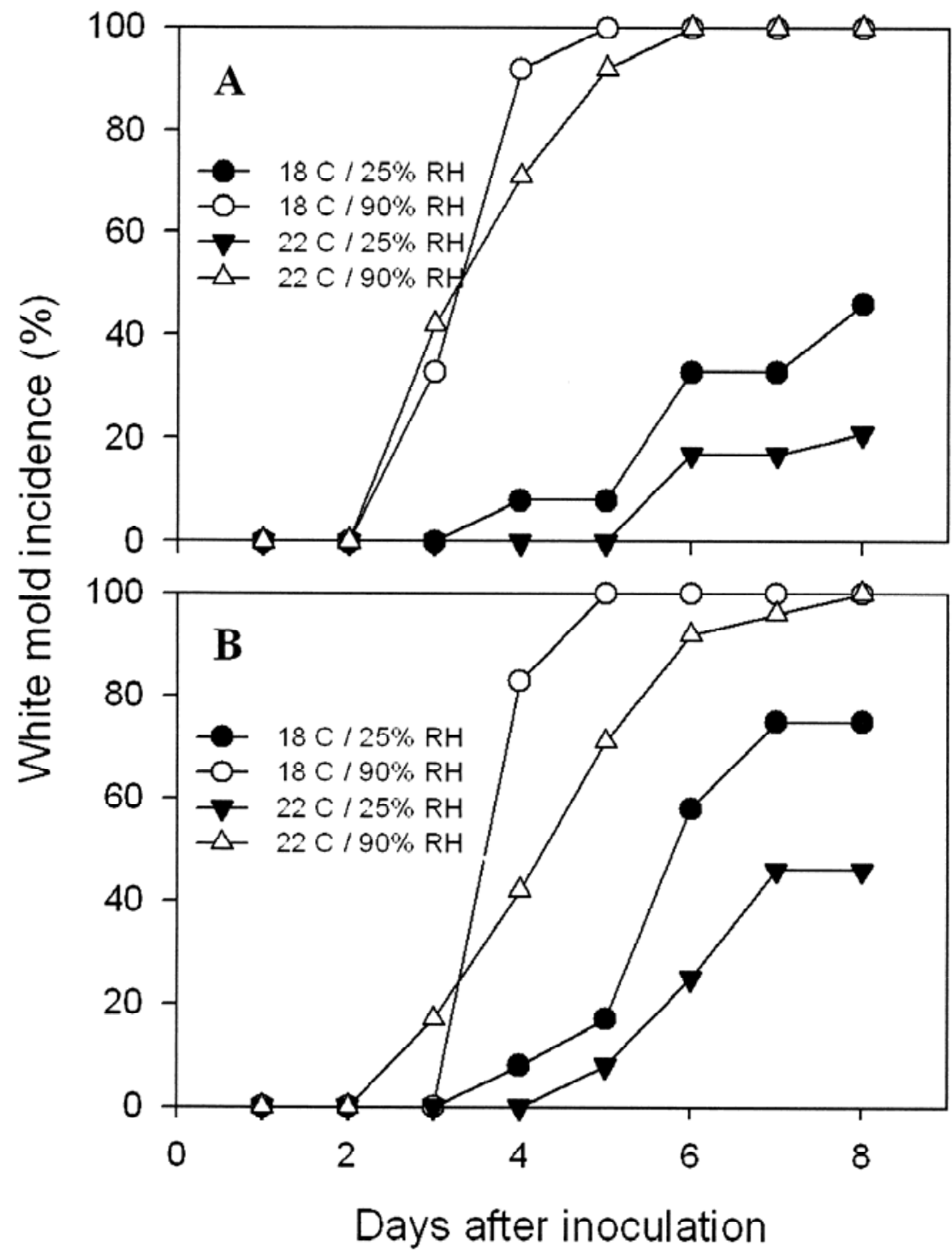

Fig. 2. Effects of temperature and relative humidity $(\mathrm{RH})$ on white mold development as initiated by $\mathbf{A}$, ascospores or $\mathbf{B}$, mycelium under growth-chamber conditions. Each data point is the mean of two experiments and three replications of five plants each.
Duration of drying study. Significant differences in time to attain $100 \%$ white mold incidence $(P \leq 0.05)$ were observed between treatments. However, on average, all the treatments achieved $100 \%$ white mold incidence within 8 days. In general, increasing the duration of drying of colonized RDBF increased the time to reach $100 \%$ white mold incidence. Colonized $\mathrm{RDBF}$ dried for $96 \mathrm{~h}$ required, on average, 2.8 days to reach $100 \%$ white mold incidence compared with colonized RDBF dried for $24 \mathrm{~h}$, which took only 1.2 days. The time to reach $100 \%$ white mold incidence by colonized RDBF was significantly affected by post-inoculation RH, duration of drying period, pre-inoculation temperature-post-inoculation $\mathrm{RH}$, preinoculation temperature-duration of drying period, post-inoculation temperatureduration of drying period, post-inoculation RH-duration of drying period, preinoculation temperature-post-inoculation temperature-duration of drying period, pre-inoculation temperature-post-inoculation RH-duration of drying period, postinoculation temperature-post-inoculation RH-duration of drying period, and the four-way interaction $(P \leq 0.05$; Table 2$)$. On average, it took an extra day to reach $100 \%$ white mold incidence in seedlings incubated at $25 \% \mathrm{RH}$ compared with seedlings incubated at $90 \% \mathrm{RH}$.

Post-inoculation RH played a significant role in white mold development. On plants inoculated with flowers dried at $18^{\circ} \mathrm{C}$ and $25 \% \mathrm{RH}$, white mold incidence reached $100 \%$ on seedlings incubated at $90 \% \mathrm{RH}$ within a day, irrespective of postinoculation temperature and duration of drying period (Fig. 3A), whereas it took more than $48 \mathrm{~h}$ to reach $100 \%$ incidence on seedlings incubated at $25 \%$ RH. Colonized RDBF dried at $22^{\circ} \mathrm{C}$ and $25 \% \mathrm{RH}$ showed a mixed response in the time to reach $100 \%$ white mold incidence under both post-inoculation temperatures and RH levels (Fig. 3B). In general, seedlings inoculated with colonized RDBF dried at $22^{\circ} \mathrm{C}$ and $25 \% \mathrm{RH}$ took longer time to achieve $100 \%$ white mold incidence than seedlings inoculated with colonized RDBF dried at $18^{\circ} \mathrm{C}$. Viability of S. sclerotiorum was not affected by either the length of drying or the conditions of drying tested. S. sclerotiorum was viable $(100 \%)$ in the colonized RDBF even after $144 \mathrm{~h}$ of drying under both conditions tested $\left(18\right.$ or $22^{\circ} \mathrm{C}$ and $25 \% \mathrm{RH}$; in vitro testing).

\section{DISCUSSION}

There are three important findings from our studies. First, white mold incidence increased with increasing ascospore concentrations. Second, ascospores successfully infected flowers and caused white mold even at RH levels as low as $25 \%$. Third, S. sclerotiorum can remain viable in the colonized flowers even after $144 \mathrm{~h}$ of 
drying and still cause white mold if appropriate conditions are provided.

White mold developed equally well at both RH levels across all ascospore concentrations, although there was an initial delay in white mold development at $90 \%$ $\mathrm{RH}$ with the lowest ascospore concentration. Studying ascospore viability on the leaf surface under in vitro conditions with various temperature and $\mathrm{RH}$ combinations, Ceaser et al. (8) reported a strong negative relationship between temperatures above $25^{\circ} \mathrm{C}$ and increasing $\mathrm{RH}$, but white mold development was not measured. However, under field conditions, they found that only total hours at or above $21.5^{\circ} \mathrm{C}$ during a 48 $\mathrm{h}$ period significantly correlated with ascospore mortality, whereas total hours at or above $60 \%$ RH was not well related. Our results corroborate their findings, although we did not directly quantify ascospore viability. Based on our results, using senescent flowers as the energy source for ascospore infection, ascospores can infect seedlings even at low RH $(25 \%)$ under the temperatures evaluated (18 and $22^{\circ} \mathrm{C}$ ). Even with the lowest ascospore concentration (two ascospores/flower), we obtained 20 to $40 \%$ white mold incidence across both RH levels tested. To our knowledge, this is the first study where ascospore concentration was studied in relation to temperature and $\mathrm{RH}$.

Under high RH (90\%), both ascospores and mycelia were equally effective in causing white mold irrespective of the incubation temperatures $\left(18\right.$ and $\left.22^{\circ} \mathrm{C}\right)$. However, under low RH (25\%), ascospores were less efficient than mycelia in causing disease at both temperatures. There are several possible reasons for this. It has been postulated that ascospores need free standing water for germination and infection $(1,4)$; because no free water was observed on the leaf surface under $25 \% \mathrm{RH}$ condition, ascospores might have germinated at a lower rate than ascospores incubated at $90 \%$ RH. It is also possible that mycelia tolerate desiccation better than ascospores and, thus, colonized plant tissues better under low RH conditions. If field conditions turn dry after flower colonization, some amount of white mold development could occur provided temperatures are in the optimum range.

$S$. sclerotiorum remained viable in colonized RDBF even after $144 \mathrm{~h}$ of drying as evaluated under in vitro conditions. $S$. sclerotiorum on colonized RDBF, irrespective of drying conditions and postinoculation temperatures, killed all the seedlings within 2 days at $90 \%$ RH. However, seedlings incubated at $25 \% \mathrm{RH}$ exhibited more variability in duration to attain $100 \%$ white mold incidence, and where affected by drying conditions and duration of drying period. Seedlings inoculated with $S$. sclerotiorum-colonized $\mathrm{RDBF}$ dried at $22^{\circ} \mathrm{C}$ and $25 \% \mathrm{RH}$ consistently reached $100 \%$ white mold incidence
Table 2. Analysis of variance of the effects of duration (h) of drying of colonized dry bean flowers by Sclerotinia sclerotiorum under two temperatures $\left(18\right.$ and $\left.22 \pm 1^{\circ} \mathrm{C}\right)$ and relative humidity $\leq 25 \%$ on days to $100 \%$ white mold incidence in dry beans

\begin{tabular}{lcccc}
\hline Source $^{\mathbf{a}}$ & df & MSE $^{\mathbf{b}}$ & $\boldsymbol{F}$ & $\boldsymbol{P}>\boldsymbol{F}$ \\
\hline Pretemp (Pret) & 1 & 0.4 & 1.3 & 0.45 \\
Postemp (Post) & 1 & 2.1 & 11.3 & 0.18 \\
Postincrh (PRH) & 1 & 196.9 & 4555.1 & $<0.0001$ \\
Dperiod (DP) & 3 & 67.2 & 1555.2 & $<0.0001$ \\
Pret $\times$ Post & 1 & 2.6 & 34.1 & 0.11 \\
Pret $\times$ PRH & 1 & 90.8 & 2098.3 & $<0.0001$ \\
Pret $\times$ DP & 3 & 16.7 & 385.2 & 0.0002 \\
Post $\times$ PRH & 1 & 0.01 & 0.33 & 0.61 \\
Post $\times$ DP & 3 & 0.5 & 11.5 & 0.04 \\
PRH $\times$ DP & 3 & 41.0 & 948.4 & $<0.0001$ \\
Pret $\times$ Post $\times$ PRH & 1 & 0.001 & 0.04 & 0.86 \\
Pret $\times$ Post $\times$ DP & 3 & 0.6 & 13.1 & 0.03 \\
Pret $\times$ PRH $\times$ DP & 3 & 32.4 & 749.1 & $<0.0001$ \\
Post $\times$ PRH $\times$ DP & 3 & 0.5 & 12.5 & 0.03 \\
Pret $\times$ Post $\times$ PRH $\times$ DP & 3 & 1.2 & 9.48 & 0.05 \\
\hline
\end{tabular}

${ }^{\mathrm{a}}$ Pret $=$ colonized dry bean flowers incubated at two temperatures $\left(18\right.$ or $22 \pm 1{ }^{\circ} \mathrm{C}$ and $25 \%$ relative humidity); Post $=$ temperatures $\left(18\right.$ and $\left.22 \pm 1^{\circ} \mathrm{C}\right)$ at which seedlings were incubated post-inoculation with colonized dry bean flowers; PRH $=$ relative humidity post-inoculation with colonized dry bean flowers; and DP = hours of drying of colonized dry bean flowers at two temperatures $\left(18\right.$ or $22 \pm 1^{\circ} \mathrm{C}$ and $25 \%$ relative humidity).

${ }^{\mathrm{b}} \mathrm{MSE}=$ mean square error.

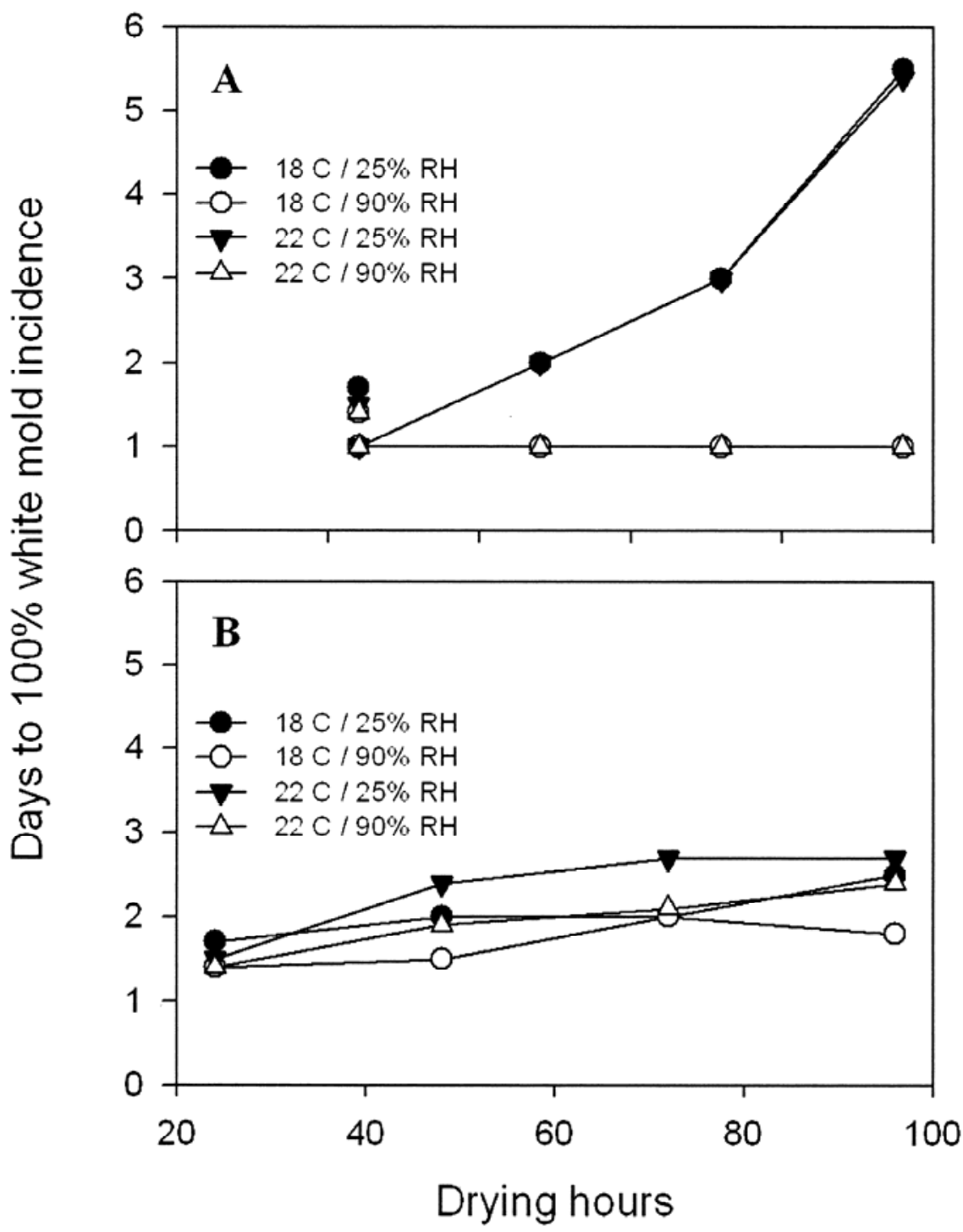

Fig. 3. Influence of incubation conditions on white mold development on dry bean seedlings inoculated with Sclerotinia sclerotiorum-colonized dry bean flowers dried at $\mathbf{A}, 18^{\circ} \mathrm{C}$ and $25 \%$ relative humidity $(\mathrm{RH})$ or $\mathbf{B}, 22^{\circ} \mathrm{C}$ and $25 \% \mathrm{RH}$. Each data point is the mean of two experiments and three replications of five plants each. 
faster than seedlings inoculated with $S$. sclerotiorum-colonized RDBF dried at $18^{\circ} \mathrm{C}$ and $25 \% \mathrm{RH}$ irrespective of postinoculation temperature and $\mathrm{RH}$. These results are similar to previous observations by Phillips (12), who, using a leaf disk assay, found that duration of drying prior to conditions conducive for infection is critical for ascospore germination, infection, and white mold development. In this study, whole flowers were inoculated and dried; however, a lower survival rate of $S$. sclerotiorum should be expected under field conditions where, potentially, both single petals and whole flowers can become infected. Additional experimentation is required to verify these results. Although mycelia is not the primary inoculum under field conditions, it could be potentially used as an inoculum source under varying environmental conditions due to its tolerance to desiccation as evidenced from our results and could be exploited further for resistance screening for white mold.

Although white mold is endemic in North Dakota, our field observations reveal extreme variation in incidence within and across fields and, more often than not, white mold incidence is mostly restricted to areas along the wind barriers (tree shelters) bordering fields. These wind barriers preserve moisture inside the bean canopy and, thus, provide an ideal environment for white mold development.

White mold is primarily a cool-season disease and is adversely affected by high temperatures $\left(>27^{\circ} \mathrm{C} ; 16\right)$. In North Dakota, the average daily temperature ranges in the mid-20s $\left(22\right.$ to $26^{\circ} \mathrm{C}, 30$-year average) during the flowering period (July), which is within the optimum range of tem- peratures reported for white mold development (16). At these temperatures and with continuous high RH (approximately 90\%), S. sclerotiorum killed inoculated seedlings in 1 to 2 days; however, this outcome might change with the age of the plant, cultivar, and field conditions, where temperature and $\mathrm{RH}$ are not constant. Although there is a trend for greater white mold development with higher RH within the temperature levels tested based on our results, the role of fluctuating $\mathrm{RH}$ and temperature levels on white mold development needs further elucidation for improvement of currently available white mold forecasting systems and disease management recommendations.

\section{ACKNOWLEDGMENTS}

The United Stated Department of AgricultureAgricultural Research Services National Sclerotinia Initiative provided partial funding for this study. We thank N. C. Gudmestad, C. A. Bradley, and T. Gulya for their critical evaluation of this manuscript; and R. Lamppa for technical help and ascospore production.

\section{LITERATURE CITED}

1. Abawi, G. S., and Grogan, R. G. 1975. Source of primary inoculum and effects of temperature and moisture on infection of beans by Whetzelinia sclerotiorum. Phytopathology 65:300-309.

2. Abawi, G. S., and Grogan, R. G. 1979. Epidemiology of diseases caused by Sclerotinia sclerotiorum. Phytopathology 69:899-904.

3. Blad, B. J., Steadman, J. R., and Weiss, A. 1978. Canopy structure and irrigation influence white mold disease and microclimate of dry edible beans. Phytopathology 68:14311437.

4. Boland, G. J., and Hall, R. 1987. Epidemiology of white mold of white bean in Ontario. Can. J. Plant Pathol. 9:218-224.

5. Boland, G. J., and Hall, R. 1988. Epidemiol- ogy of Sclerotinia stem rot of soybean in Ontario. Phytopathology 78:1241-1245.

6. Boland, G. J., and Hall, R. 1994. Index of plant hosts of Sclerotinia sclerotiorum. Can. J. Plant Pathol. 16:93-108.

7. Bradley, C. A., and Luecke, J. L. 2003. 2002 dry bean grower survey of pest problems and pesticide use in Minnesota and North Dakota. N. D. State Univ. Ext. Rep. No. PP 1265.

8. Caesar, A. J., and Pearson, R. C. 1983. Environmental factors affecting survival of ascospores of Sclerotinia sclerotiorum. Phytopathology 73:1024-1030.

9. Harikrishnan, R., and del Río, L. E. 2004. Effects of temperature (TEMP) and relative humidity (RH) on ascosporic infection, and viability of pre-colonized flowers by Sclerotinia sclerotiorum on white mold (WM) development in dry beans. (Abstr.). Phytopathology 94:S39.

10. Harikrishnan, R., del Río, L. E., and Lamppa, R.S. 2004. Prevalence of dry bean diseases in North Dakota-2003. (Abstr.). Phytopathology 94:S39.

11. North Dakota Agriculture Statistics 2003. Pages 71-74 in: North Dakota Agriculture Statistics Service, Volume 72.

12. Phillips, A. J. 1993. Influence of fluctuating temperatures and interrupted periods of plant surface wetness on infection of bean leaves by ascospores of Sclerotinia sclerotiorum. Ann. Appl. Biol. 124:413-427.

13. Schwartz, H. F., Steadman, J. R., and Coyne, D. P. 1978. Influence of Phaseolus vulgaris blossoming characteristics and canopy structure upon reaction to Sclerotinia sclerotiorum. Phytopathology 68:465-470.

14. Sun, P., and Yang, X. B. 2000. Light, temperature, and moisture effects on apothecium production of Sclerotinia sclerotiorum. Plant Dis. 84:1287-1293.

15. Tu, J.C. 1989. Modes of primary infection caused by Sclerotinia sclerotiorum in navy bean. Microbios 57:85-91.

16. Weiss, A., Kerr, E. D., and Steadman, J. R 1980. Temperature and moisture influence on the development of white mold disease (Sclerotinia sclerotiorum) on Great Northern beans. Plant Dis. 64:757-759. 